\title{
GENERAL PRACTICE AND MEDICAL EDUCATION
}

We print below four articles from contributors who have been active in the work of the College of General Practitioners and of its committees. The first three discuss the undergraduate and continuing education of the general practitioner, and the fourth is the report of a working party on psychological medicine in general practice.

\section{UNDERGRADUATE EDUCATION AND THE GENERAL PRACTITIONER}

BY

\author{
RICHARD SCOTT, M.D., D.P.H. \\ Reader in General Practice, University of Edinburgh, \\ Chairman, Undergraduate Education Committee of the \\ Council of the College of General Practitioners
}

The Hippocratic Oath ${ }^{1}$ binds us to look upon the sons of our teachers as our own brothers, and " to teach them this art if they shall wish to learn it." We undertake to impart a knowledge of the art to our own sons and those of our teachers, and to do this "by precept, lecture, and every other mode of instruction." It is appropriate to begin this review with a reference to Hippocrates, since those of us who have had the privilege of membership of the College of General Practitioners from its foundation, less than six years ago, can detect a new awareness of the professional ties which bind us together as family doctors.

Early fears that the creation of yet one more medical college would merely serve further to divide our profession have not been realized. Far from dividing us, the College has not only provided, in the form of an academic institution, a vehicle for the expression of our common heritage as general practitioners, but it has also enabled us to re-examine our relationships with our colleagues working in the many other branches of our profession. This in turn has led us to take the first step towards our reintegration as members of a single united profession.

Of all the spheres of interest of the College none has provided a greater stimulus to this way of thinking than the field of undergraduate education. By examining in retrospect our own training as medical students against the background of the work we have had to do since leaving our several medical schools, by meeting the medical students who have taken our places in the lecture theatres, laboratories, and clinics, and by discussing with them the present-day problems of medical education, we have developed a sense of thinking of these students as indeed our professional heirs. It may be that some of us are so overwhelmed by the magnitude and urgency of the problems encountered in general practice that we see little likelihood of our being able to solve these problems in our own lifetime. We are beginning to look to the next generation to assist us in our work, and eventually to take up themselves the challenge which we have but partially met.

There are 25 regional faculties of the College in the United Kingdom and Eire. Their boundaries have been drawn up so as to ensure that, wherever possible, the headquarters of a faculty will be alongside a university with a medical school. The board of each faculty has a standing committee dealing with undergraduate education, the aim of which is to establish close liaison between the College and this medicai school. The work of these committees has been described in detail in a booklet published last month. ${ }^{2}$ Three other publications of the College discuss our policy and aims with regard to undergraduate education, and give specific examples of the ways in which general practitioners are already assisting in the training of medical students. These are: "The Teaching of General Practice by General Practitioners,"3 "The Medical Curriculum," and "Recommendations as to the Medical Curriculum "s submitted by our College to the General Medical Council.

We recognize that the training of medical students is the responsibility of medical schools, working within the broad terms of reference drawn up for them by the General Medical Council, which itself reviews every 10 years its own standing recommendations on the medical curriculum. These recommendations are purposely framed so as to encourage each school to take the initiative in experimenting with its curriculum. General practitioners can make no contribution to the training of the medical student unless they are invited by medical schools to do so.

Against this background I propose to examine the suggestion made by the General Medical Council that " it is desirable that the student should be given opportunities to learn something of the work of the general practitioner." In this paper I shall pose five questions and discuss the answers to them: (1) Why is it desirable that students should be introduced to general practice ? (2) At what stage in the curriculum should this occur ? (3) Where should it take place ? (4) How should this introduction of students to general practice be carried out ? and (5) What should they be taught?

\section{Why Ought Students to be Introduced to General Practice?}

In order to answer this question we have to examine some facets of the evolution of medicine, particularly during the past century. Those that are particularly relevant are: the growth of medicine as a scientific discipline, the evolution of specialization, the interaction between medicine and the social sciences, and the emergence of the provision of comprehensive medical care on a national scale as an integral part of the health and welfare services of the community. This represents an arbitrary isolation of some facets only of medical progress. None of these subjects can be considered on its own, since each reacts upon the other. I wish merely to underline those features of the evolution of medicine which are particularly relevant to the problem we are examining.

\section{Evolution of Medicine}

During the past hundred years the securing first of pathology and then of bacteriology on a sound scientific basis, the rapid growth of chemistry followed by the expansion of physiology and of our knowledge of metabolism, laid the basis for the rapid growth of medicine as an applied science. The rapid development of the basic medical sciences led first to a differentiation between the preclinical and clinical subjects taught to students Of more importance, however, is the fact that it led to a d f ferentiation between the preclinical and clinical teachers. This differentiation has been carried further, in that in 
many medical schools those who teach the preclinical subjects are not themselves medically qualified. The demand for increased emphasis on the scientific basis of medicine is just and inexorable. It has, however, resulted in a differentiation between those who teach and those who practise medicine. This differentiation has in more recent years been carried into the clinical part of the curriculum. The necessity to present the detailed scientific basis of clinical diagnosis and treatment has brought about the tendency to divorce the academic from the practical. One of the inevitable consequences of a rapid growth of knowledge is the evolution of specialization. It is relevant to examine here some of the by-products of specialization in so far as they have a bearing on medical teaching.

\section{Specialization}

The teaching hospitals and research institutes associated with our medical schools provided the focus and took the initiative in the advancement of medicine as a scientific discipline, and in consequence it is in our medical schools that we find the most extreme forms of specialization. The general physician has practically disappeared from the clinical teaching staff. More and more our medical students during the years of their clinical instruction are being introduced not only to the techniques but also to the analytical approach of the specialist. The specialist tackles the problem presented to him in the laboratory or in the clinic from the point of view of scientific analysis. By breaking down the problem to its component parts, and by further analysis, the specialist proceeds to a solution of the diagnostic dilemma or the advancement of his researches. It is in this atmosphere that the student is conditioned for his lifetime's work, whether that should lie in the hospital, in general practice, or in any other medical sphere.

In contradistinction to this analytic approach of the specialist, the actual practice of medicine-that is, the process involved in the doctor-patient relationship-calls for an approach which is one of synthesis. The doctor may well begin with an analysis of physical signs and symptoms, but the essential feature of the challenge presented to him by the patient is that of putting this scientific information alongside his knowledge of the patient as a person, as a member of a family, as an employee or employer, and so forth, so as to arrive at a picture of the patient as a whole person. Unless he instinctively and automatically approaches his work with this attitude of mind, the doctor will fail to make an adequate and complete medico-social diagnosis on which to base his attempts to work through with the patient to a solution, or at least a mitigation, of his problem.

In the clinical subjects, the trend towards full-time teaching and research appointments has accelerated in recent years. This in turn must lead to a further decline in the number of teachers who have a substantial and continuing daily responsibility for the provision of medical care for patients in open society.

One of the phenomena of specialization is that a subject advances by a process of dichotomy. It is not inevitable, however, that two new subjects shall appear. In all clinical subjects, advances sometimes take the form of narrowing the field by sloughing off some of the content of the subject into the undifferentiated field of general practice. In this sense-and this particularly applies to more recent times-what belonged to hospital or laboratory medicine yesterday is to be found in general practice to-day. There is in fact a two-way traffic between hospital medicine and general practice. One possible implication of this is that medical teachers may in future years have to come out of the hospital into general practice to find the clinical material on which students will be taught-not social medicine, preventive medicine, general practice, or psychological medicine, but in fact, and quite simply, clinical medicine.

Specialization is a necessary and a desirable feature of medical progress. Many of our most urgent problems can- not be resolved without further specialization of knowledge and practice. While as general practitioners we welcome specialization, we are of the opinion that special efforts are required to counteract some of its unfortunate but not inevitable by-products. One of these is the impact which specialization at university level is having on trends in premedical education. The granting of exemption from the first professional examination to suitably qualified aspirants for entry into the medical schools has provided an additional incentive to school teachers to encourage their pupils who hope to become medical students to specialize very early in their school careers in scientific subjects, to the exclusion of the liberal arts and humanities.

\section{Medicine and the Social Sciences}

The dramatic introduction of chemotherapy and later of the antibiotics has revolutionized our patterns of morbidity and mortality. We are now much more concerned with the psychological and human relationship factors than with the physical features of man's environment in our search for the major causes of human suffering, misery, and disease. Creeds are indeed much more important than cocci. While we owe a great deal to the contributions made by the psychiatrist in our understanding of the factors which are inimicable to mental health, recent advances in our knowledge of man as a social animal have derived as much from the advances of the social sciences as from contributions from medicine. The increasing complexity of our social institutions and of our rapidly developing social services lead many of us to believe that the medical student requires to be more adequately equipped than he is at present with a knowledge not only of human anatomy and physiology but also of the anatomy and physiology of the society in which he will later practise his profession.

\section{Provision of Comprehensive Medical Care on a National Basis}

The National Health Service provides the framework within which the hospital and specialist services and the public health services can be related to the service provided by the family doctor. Since practically all demands for medical care are initiated at the general-practitioner level, it is in his consulting-room that we are most likely to see the first signs of changes in need and changes in demands for medical care. Members of the general public now possess, in the form of a domiciliary medical service, an eloquent means of expressing their need for an integration of the medical services as a whole, and for closer integration between the medical services and the existing social services. Since our medical schools provide the basic training for all doctors who man this service, they have a special responsibility to study these and other changes which are taking place in the practice of medicine in this country. These changes must in time be reflected in the medical curriculum so that every graduate, wherever his destiny lies, is at least aware of the nature of the work of the family doctor and the relationship which this is likely to have in future years to the contribution made by medical men in other fields.

I would summarize as follows my answers to the question, Why is it desirable that the student should be given opportunities to learn something of the work of the general practitioner? The rapid development of the science of medicine and the evolution of specialization have resulted in the emergence of a new generation of medical teachers who have little or no practical experience of the work of the general practitioner. The clinical and practical teaching in hospitals is becoming concerned more and more with episodes of illness, with categories of disease, and with categories of individuals. The student sees medicine at work in a situation where the nature of the clinical or social problem of the patient is predetermined and selected by the doctor. In contrast to this, the general practitioner is faced with a situation in which he cannot determine beforehand the kind of clinical or social problem with which 
his patient will challenge him. It is only in the setting of general practice, therefore, that the student can be given some insight into the wide range of clinical and social problems with which society confronts the medical profession.

The practice of medicine is undergoing rapid change, both as a result of developments in medicine itself and from social pressures being exerted by the community. Trends in specialization are likely to lead us to more energetic efforts to promote collaboration between the several branches of the medical profession and workers in the social services and related fields. An exposure of the student to general practice therefore does not constitute merely an antidote to the philosophy and attitude of mind of the specialist, it should provide that student with an opportunity to learn how he can become a better specialist, enable him to apply the knowledge which he has already acquired, and imbue him with a sense of the indivisibility of medicine. Our College does not advocate vocational training for general practice during the undergraduate years, but recommends that the field of general practice should be exploited in order to widen the professional horizons of the next and succeeding generations of medical graduates.

I have spent some time answering the question Why? because an examination of the factors which make it desirable that the student should be shown something of the work of the general practitioner will itself suggest the answers to the subsidiary questions When? Where? How ? and What?

\section{When Should the Student be Introduced to General Practice ?}

A questionary sent out in the early days of the College's existence revealed that the majority of our members and associates agreed that the student should be introduced to general practice. A substantial number, however, were of the opinion that this introduction would be most effectively made during the pre-registration year or even a little later. We have moved considerably away from this point of view, and are convinced that every student should have this experience while still an undergraduate, as part of his basic training. The student should be helped to correlate this experience with the teaching he is receiving during his clinical years. For example, he should have some experience of the problem of prescribing in the setting of general practice, at the same time as he is being taught therapeutics. If he has had an opportunity while he is still attached to a teaching ward to follow patients through from the wards to their homes and to see the kind of problems these patients present to their family doctor, he is less likely to think of rehabilitation and aftercare as a special branch of medicine, and will begin to appreciate that there is an element of rehabilitation and readjustment confronting every patient when he leaves hospital.

It having been decided that the student should be exposed to this experience during his stay in the medical school, a more difficult question to resolve is at what point in the curriculum should this experience be offered ? While it is suggested that the experience which can be obtained in general practice should permeate all the clinical years, and the student should be helped to integrate what he learns in general practice with all that he is being taught in his last three years at medical school, there is much to be said for introducing this subject rather late in the curriculum. If the exigencies of the curriculum allow for only one period of practical experience in general practice, two arguments can be presented in support of the recommendation that this should appear later rather than early in the curriculum. Those of us who have had students in our practices are of the opinion that the less the student knows about medicine the easier it is to arouse his interest in the patient as a person and a member of society. By the time that he is approaching the end of the curriculum, however, he has become much more interested in the dis- ease than in the sick person, and the experience of general practice is most effective at this stage in providing an antidote and a challenge to his own philosophy and point of view.

A vivid first reaction of most students on being exposed to the unselected morbidity which presents itself to the general practitioner is a preoccupation with the quantity of clinical material which they classify as belonging to the specialties, particularly dermatology, ophthalmology, oto-laryngology, paediatrics, and psychiatry. The student is introduced to public health and social medicine at a late stage in the curriculum. A great deal of the work of the family doctor lies in the field of preventive medicine, and the student will gain very much more from the experience if he has already received some systematic instruction in the subject. If schemes of attachment are to be developed so that the student will not be merely an observer but will be given some delegated responsibility for the care of patients in their own homes-learning by doing - he should have at least a nodding acquaintance with these major specialist fields.

\section{Where Should this Instruction be Given?}

The obvious answer to this question is in the practical day-to-day setting of general practice. If we leave aside the general practitioner himself, the field of general practice offers unique opportunities for practical instruction and for challenging the student to think about what he has been taught elsewhere. That this is widely appreciated is illustrated by the diversity of teachers who have taken the initiative in introducing students to general practice. In some medical schools this has been done at the instigation of the dean, in others by a senior physician or surgeon. In others, the psychiatrist, the paediatrician, or the head of the department of public health and social medicine has taken the initiative, and in at least one school the bacteriologist has encouraged this activity.

This teaching need not, however, be confined to the setting of general practice. The general practitioner has in some centres brought his patient to the hospital and has taken part in seminars and discussion groups. These are of great assistance to the student in helping him to integrate the hospital and the domiciliary components of the diagnostic and therapeutic problems presented by the patient. More important than this, they enable the student to see an actual consultation take place between the general practitioner and the specialist.

\section{How Should it be Taught?}

There is practically no educational method which cannot be applied to this subject-."By precept, lecture, and every other mode of instruction." Among the most valuable of all methods is that of attaching the student for a period of two weeks or more to a general practitioner. When fully developed these attachment schemes will enable the student to progress from the passive observer role to a modified apprenticeship. The student is taken right into the doctorpatient consultation in the surgery or in the patient's own home. He sees what the doctor does at the very beginning of the consultation before the clinical problem has been posed. The student is able to observe how the doctor reacts when confronted with the necessity of finding answers to Halliday's questions ${ }^{7}$ : What kind of person is this patient ? Why did he take ill when he did? Why did his illness take the form that it did?

With a view to being able to answer any appeal from a medical school for help in providing general practitioners who are willing to take students into their practices, our College has produced a register containing the names of more than 1,300 general practitioners who have volunteered to assist in this work. More than $\mathbf{4 5 0}$ of these general practitioners are willing to have the student remain in their practices for an extended period of a week or more. The 
remainder are willing to take students from the nearest medical school on a day-to-day basis, on a number of occasions each year. This register has been broken down on a regional basis, and local lists giving full particulars are available at the headquarters of each of our faculties in the United Kingdom and Eire.

The very essence of this kind of teaching is the introduction of the student to the patient by his general practitioner. Many of us are convinced that the most important of all teachers is the patient himself. In the familiar surroundings of his own home and in the presence of his own doctor the patient is more relaxed, more eloquent, and more expressive than he is in a hospital bed. Students repeatedly emphasize the value of home visits in helping them to appreciate the subtleties of the social, economic, and psychological factors of the patient's environment.

\section{What is the Student to be Taught ?}

The College accepts, without reservation, that the chief aim of the medical school is to provide basic training for all students. The medical school is not primarily concerned with the provision of vocational training for general practice or for any other branch of medicine. We are therefore of the opinion that, while the student should be taught something about the nature of general practice and given as much insight as possible into the significance of the granting of direct and continuing access of the members of the public to the services of a general practitioner, we are just as interested, possibly more interested, in the basic training of the student who is not going to enter general practice-the future consultant, teacher, research worker, and administrator.

Current trends in morbidity and the nature of the factors which select the kind of clinical material available to medical schools may themselves lead to a movement of the centre of gravity of the medical school from the hospital towards the community, so that medical teachers may in the future come to general practice in order to teach medicine. We are of the opinion that the most important things to be learned in general practice are the intangibles, a philosophy or an attitude of mind. While, therefore, we think that the student has much to learn of a practical nature by studying the contents of the doctor's bag, with the limited time at his disposal we would prefer that he should be given the opportunity of seeing what is inside the doctor's mind. Above all, we would emphasize that it is the practical demonstration of medicine actually at work in open society which is important. It is one thing to tell a student that there are no diseases but only sick persons it is another thing to manoeuvre him into a doctor-patient relationship so that he can make this discovery for himself.

While I must accept personal responsibility for the views I have expressed, I have made a particular effort in preparing this paper to reflect as faithfully as I could the views and opinions held by members of my Committee and of the Council of the College. I have borrowed freely from their thoughts and writings. I acknowledge the great indebtedness I owe to my own teachers and to the many others with whom I have had the privilege of working since I entered this profession. My thanks are particularly due to my own patients, who have cheerfully accepted our students and contributed freely both to their instruction and to my own.

\section{REFERENCES}

1 Hippocrates: The Genuine Works. Translated by F. Adams, Sydenham Society, London, 1849.

" On Undergraduate Education and the General Practitioner," J. Coll. gen. Pract., 1, No. 3, Suppl. p. 1

3 Brit, med, J., 1953, 2, 36

4 Ibid.. 1954, 1, 1146.

s Third Annual Report, College of General Practitioners, 1955, Practitioner. 175, Suppl. p. 89

- Recommendations as to the Medical Curriculum, 1957, p. 11. General Medical Council.

' Halliday, J. L., Psychosocial Medicine, p. 30. London, 1948.

\section{POSTGRADUATE EDUCATION FOR THE GENERAL PRACTITIONER}

BY

\section{GEORGE SWIFT, B.M., B.Ch.}

General Practitioner, Winchester;

Chairman, Postgraduate Education Committee of the

Council of the College of General Practitioners

In this article the problems of the education of newly qualified doctors who wish to enter general practice, and of the continuing education of established general practitioners, are discussed in outline.

\section{Nature of the Problem}

Dr. David Hughes in his James Mackenzie Lecture! tells us of the old doctor, whom he joined in practice, who had been carrying out much the same procedures and using much the same drugs for the previous fifty years. In those days advances in medicine were comparatively few, and a respectable interval elapsed between each epoch-making discovery. An occasional visit to a teaching hospital and the reading of one or two journals were enough to keep the family doctor up to date not only in his own subject but in the whole of medicine and surgery.

Since then we have experienced a therapeutic revolution, which was heralded by the discovery of prontosil in 1935 and a political revolution in 1948-the arrival of the Welfare State and the National Health Service. Between them these two revolutions have changed medicine so dramatically that many of the skills of practitioners of twenty-five years ago are unacceptable to-day. Innumerable techniques and methods have had to be pruned and others grafted in their place to enable the older practitioner to keep up to date. New drugs, new techniques, and new methods continue to appear so regularly now that the newly qualified doctor is soon behind the times if he does not embark at once on postgraduate study. A high proportion of the prescriptions written now by the family doctor could not have been written twenty years ago because the drugs did not then exist. The general practitioner must know which new drugs, investigations, and methods to adopt, and which of the old to reject. He must keep broadly in touch with what is being done in the specialized branches of medicine so that he will not unwittingly withhold from his patients the benefits of recent developments, such as those in the surgery of the heart, the lungs, or the eyes. At the same time he must make sure that his patients are directed to the right consultant so that they do not embark upon the souldestroying tour of many special departments which can so easily add psychoneurosis to an undiagnosed physical illness.

In the Fourth Annual Report of the College of General Practitioners ${ }^{2}$ we read: "If the family doctor's professional and academic standing is to bear comparison, at all times, with that of his colleagues in other branches of the profession, he must look to his intellectual development and progress throughout his career. The College of General Practitioners has come into existence, in large part, to satisfy this need, which it can do through its regional faculties."

The College of General Practitioners has now more than thirty faculties in the United Kingdom and overseas, most of which correspond with the area served by a university with a medical school. Each faculty board has its own postgraduate education committee which attempts to coordinate the opportunities for the postgraduate education of members and associates of the College within its own area, and to increase these opportunities where necessary. The faculty boards do not in any way interfere with the work of the deans of postgraduate studies in the universities, though if and when they are invited they may be able to do much to help in the planning and organization of courses for family doctors at the medical schools and hospitals in their areas. 